\title{
Sage: The functional novel natural medicine for preventing and curing chronic illnesses
}

\author{
Rafie Hamidpour, Soheila Hamidpour, Mohsen Hamidpour, \\ Mina Shahlari
}

\begin{abstract}
Sage (Salvia) species have been used for centuries, worldwide as culinary herbs as well as traditional remedies for the treatment of many common health complications and their symptoms. In recent decades, more studies have been performed on the effect of sage in preventing, controlling, or curing various diseases naturally and more safely. Anumber of sage family members especially Salvia officinalis (common sage) and their components have shown to be beneficial in protecting the body against oxidative stress, free radical damages, angiogenesis, inflammation, bacterial and virus infection, etc. Several studies suggest that sage might potentially provide novel natural treatments for the relief or cure of many serious and life-threatening diseases in addition to treating minor common illnesses such as depression, dementia, obesity, diabetes, lupus, autism, heart disease and cancer.
\end{abstract}

Keywords: Sage (Salvia species), Salvia officinalis, Traditional remedies

$* * * * * * * * *$

Rafie Hamidpour ${ }^{1}$, Soheila Hamidpour ${ }^{2}$, Mohsen Hamidpour ${ }^{3}$, Mina Shahlari ${ }^{4}$

Affiliations: ${ }^{1} \mathrm{PhD}$, President, Pars Bioscience, Leawood, Kansas, United States; ${ }^{2} \mathrm{MD}$, Pars Bioscience, Leawood, Kansas, United States; ${ }^{3} \mathrm{PhD}$, Pars Bioscience, Leawood, Kansas, United States; ${ }^{4} \mathrm{BA}$ in Biology, Pars Bioscience, Leawood, Kansas, United States.

Corresponding Author: Rafie Hamidpour, Pars Bioscience LLC, 14109 Cambridge Lane, Leawood, Kansas, UNITED STATES. 66224; Ph: (913) 432-0107; Email: rafi@ parsbioscience.com; Fax: (913) 432-5708

Received: 16 November 2013

Accepted: 11 January 2013

Published: 01 December 2013
Hamidpour R, Hamidpour S, Hamidpour M, Shahlari M. Sage: The functional novel natural medicine for preventing and curing chronic illnesses. International Journal of Case Reports and Images 2013;4(12):671-677.

$* * * * * * * * *$

doi:10.5348/ijcri-2013-12-408-RA-2

\section{INTRODUCTION}

The genus Salvia, commonly called sage, is the largest member of Lamiaceae or mint family containing over 900 species throughout the world $[1,2]$. The plants are mostly aromatic, perennial, with flowers in different colors [3]. Many species of Salvia, including Salvia officinalis (common sage) are native to Mediterranean region and some of the Salvia species have been used worldwide as flavoring spices as well as traditional herbal medicine $[3,4]$.

Sage tea has been traditionally used for the treatment of digestive and circulation disturbances, bronchitis, cough, asthma, angina, mouth and throat inflammations, depression, excessive sweating, skin, and many other diseases [5-7]. Essential oils of Salvia have been used in the treatment of large range of diseases such as, nervous system, heart and blood circulation, respiratory, digestive, metabolic, and endocrine diseases. In addition, sage essential oil has shown to have carminative, antispasmodic, antiseptic and astringent properties [8, 9].

The essential oil of Salvia species can have various compositions depending on the genetic, climates, season, and environmental factors [10] (Table 1). There are some chemical compounds such as flavonoids, terpenoids and essential oils present in different species of Salvia [3]. Essential oils are very important sources for the screening of anticancer, antimicrobial, antioxidant, and free radical scavenging agents [11]. Salvia officinalis is considered to have the highest amount of essential oil compared to the other species of Salvia [5, 12]. 
In all analyzed samples of $S$. officinalis, the major components, although in different extent are: 1,8-cineole, camphor, borneol, bornyl acetate, camphene, $\alpha$-and $\beta$-thujone, linalool, $\alpha$-and $\beta$-caryophyllene, $\alpha$-humulene, $\alpha$ - and $\beta$-pinene, viridiflorol, pimaradiene, salvianolic acid, rosmarinic acid, carnosolic acid, ursolic acid, etc. $[7,12]$. Studies have shown that some biological properties of the essential oil of salvia, depend on camphor, 1,8-cineole, $\alpha$-thujone and $\beta$-thujone [9]. The essential oil of sage contains about $20 \%$ camphor, and as the leaves expand, the camphor contents also

Table 1: Essential oil composition (\% of major components) of sage Salvia officinalis collected as a sample [5].

\begin{tabular}{|c|c|c|}
\hline Compound $^{1}$ & S. Officinalis ${ }^{2}$ & S. Officinalis ${ }^{3}$ \\
\hline$(1 \mathrm{R})-(+)$-a-Pinene & 3.70 & 4.50 \\
\hline (-)- Camphene & 2.60 & 5.00 \\
\hline B- Pinene & 6.00 & 5.20 \\
\hline Sabinene & - & 0.30 \\
\hline B- Myrcene & 3.00 & 3.50 \\
\hline a-Terpinene & - & 0.40 \\
\hline (R)-(+) Limonene & - & - \\
\hline 1, 8 - Cineole & 62.0 & 55.0 \\
\hline Y- Terpinene & 0.30 & 0.50 \\
\hline P-Cymene & 0.60 & 0.60 \\
\hline Terpinolene & - & 0.20 \\
\hline (-)-a-Thujone & 1.38 & 1.80 \\
\hline B-Thujone & 0.72 & 1.50 \\
\hline Camphor & 8.0 & 10.0 \\
\hline (-)-Linalool & 0.80 & 0.80 \\
\hline Linalyl acetate & 0.60 & 0.30 \\
\hline $\begin{array}{l}\text { (-)-Trans- } \\
\text { Caryophyllene }\end{array}$ & 2.00 & 1.00 \\
\hline Monoterpene & 1.26 & 1.10 \\
\hline (+)-Menthol & - & - \\
\hline Borneol & 5.00 & 4.50 \\
\hline a- Terpineol & 0.20 & - \\
\hline Geranyl acetate & 0.30 & - \\
\hline Geraniol & 0.10 & 0.25 \\
\hline Phytol & 0.18 & - \\
\hline Thymol & 0.80 & 0.70 \\
\hline Carvacrol & 0.20 & 0.40 \\
\hline Farnesol & 0.20 & - \\
\hline $\begin{array}{l}\text { Tran s - t r a n s - } \\
\text { Farnesol }\end{array}$ & 0.06 & 0.15 \\
\hline Total Components & 45 & 30 \\
\hline
\end{tabular}

${ }^{1}$ Compounds of essential oil extracted from fresh green leaves and flowering top.

${ }^{2}$ Collected at $100 \mathrm{~m}$ above the sea level.

${ }^{3}$ Collected at $500 \mathrm{~m}$ above the sea level. increases [13]. The better radical scavenging activities of $S$. officinalis essential oil might be because of the high content of 1,8-cineole [11].

Sage is also a natural source of flavonoids and polyphenolic compounds (e.g., carnosic acid, rosmarinic acid and caffeic acid) possessing strong antioxidant, radical-scavenging and antibacterial activities [14]. The majority of the phenolic acids in salvia species are derivatives of caffeic acid which is the building block of a variety of plant metabolites. Caffeic acid plays a central role in the biochemistry of the Lamiaceae and occurs mainly in dimmer form as rosmarinic acid (Figure 1) [15, 16]. Carnosic acid and rosmarinic acid which are present at high concentration in the extract of sage plants, have shown strong antioxidant properties [17]. Ursolic acid, a component of sage, has strong anti-inflammatory properties and in sage preparations, is considered as a quality control measurement for the anti-inflammatory effects of different solutions [18].

Antioxidant: Antioxidants play a very important role to protect the body against the oxidative stress and free radical damages which are the cause of various ailments such as diabetes, heart diseases, cancer, brain dysfunction, weakened immune system and many more $[19,20]$.

In a study done on the antioxidant activity of many plant extracts, like sage (Salvia officinalis), it was found that the phenolic and flavonoid compounds are mainly responsible for the antioxidant and free radical scavenging effect of these plants [20, 21]. Phenolic compounds such as carnosol, carnosic and rosmarinic acids, rosmadial, rosmanol, epirosmanol, methyl carnosate and luteolin-7-O-betaglucopyranoside have a high antioxidative activity and are usually extracted from sage with ethanol [22]. The phenolic compounds can either stimulate endogenous antioxidant defense systems or scavenge reactive species [23].

The antioxidant properties of sage have been studied intensively, and are found to be related to the presence of rosmarinic acid and carnosic acid [24, 25]. In addition, salvianolic acid which is a rosmarinic acid dimmer, isolated from the sage extract showed a great antioxidant activity and is a very significant scavenger of free radicals [25] (Figure 2). The aqueous extract of $S$. officinalis has shown to have antioxidant and antiviral effect and in a study, after drinking of sage tea for two weeks the liver antioxidant status improved as a result [26].

Memory: Amongst many herbal extracts, Salvia species are known for the beneficial effects on memory disorders, depression, and cerebral ischemia [27]. Salvia officinalis, Salvia lavandulaefolia (Spanish sage), and Salvia miltiorrhiza (Chinese sage) have been used for centuries as restoratives of lost or declining mental functions such as Alzheimer's disease [19, 27]. In Alzheimer's disease, the enzyme acetyl cholinesterase (AChE) is responsible for degrading and inactivating acetylcholine, which is a neurotransmitter substance involved in the signal transferring between the synapses. Acetyl cholinesterase inhibitor drugs act by counteracting 


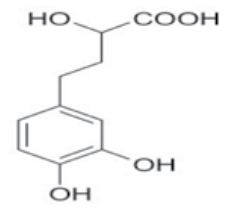

Danshensu

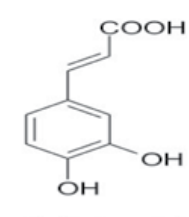

Caffeic acid

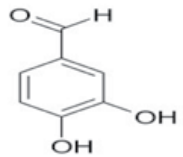

Protocatechualdehyde

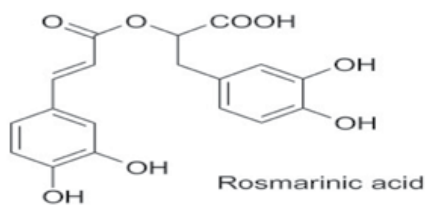

Figure 1: Danshensu and monoterpenoids from S. miltiorrhiza. All of these compounds contain catechol functionalities [16].
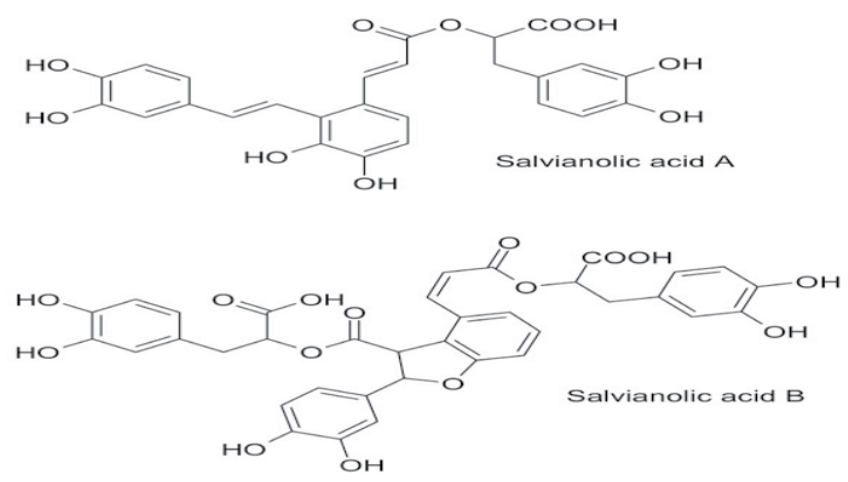

Figure 2: Salvianolic acids from $S$. miltiorrhiza. All of these compounds contain catechol moieties [16].

the acetylcholine deficit and enhancing the acetylcholine in the brain. Essential oil of Salvia officinalis have shown to inhibit $46 \%$ of acetylcholinesterase activity at a concentration of $0.5 \mathrm{mg} \mathrm{mL}^{-1}$ [28].

A study shows that Salvia officinalis improves the memory and cognition, and with the increase of the dosage, the mood elevation increases as well as alertness, calmness, and contentedness [29]. A randomized, double blind clinical study has shown that an ethanolic extract from $S$. officinalis and $S$. lavandulaefolia is effective in the management of mild to moderate Alzheimer's disease, and this study did not show any adverse effects on patients while taking sage [30, 31]. Administration of Salvia lavandulaefolia has been reported to be effective on the improving the speed of memory and mood. Salvia essential oil also has been reported to improve immediate word recall [19].

A number of studies have investigated the effects of the aromas of plant essential oils on cognition and mood. Salvia officinalis aroma produced a significant enhancement effect for the quality of memory factor derived from cognitive drug research system. The findings suggest that the aromas of essential oils of Salvia species have some but not all of the effects found following the oral consumption of the herb [32]. The antioxidant and anti-inflammatory properties of the $S$. officinalis or $S$. lavandulaefolia may offer a long-term protection in the pathogenesis of the dementia. Also the mood enhancing properties of the herb may have applications in the treatment of advanced dementia, in which disturbed mood and agitation feature as a major problem. There is no report of negative side effects associated with $S$. officinalis or $S$. lavandulaefolia despite of many years of usage span [29].

The cytoprotective effect of sage against $\mathrm{A} \beta$ (amyloid beta plaques) toxicity in neuronal cells also has been proven by the data presented in a study which provides the pharmacological basis for the traditional use of sage in the treatment of Alzheimer's disease. Rosmarinic acid as a component of sage has shown neuroprotective, antioxidative, and anti-apoptotic effects against $\mathrm{A} \beta$ toxicity and this could contribute, at least in part, to the neuroprotective effect of sage. Therefore, it is possible that rosmarinic acid, this very low toxic natural compound could be used as a therapeutic agent in the treatment of Alzheimer's disease [31].

Diabetes: Salvia officinalis has been used as a traditional remedy against diabetes in many countries and its glucose-lowering affects have been demonstrated in animal studies. In a study, it was found that methanolic extracts of $S$. officinalis significantly decreased serum glucose in type I diabetic rats without affecting pancreatic insulin production. An aqueous extract of Salvia officinalis have been found to exhibit insulin-like activities [33].

In a study, drinking of sage tea, $(300 \mathrm{~mL}$, twice a day) showed the increase in antioxidant defenses and improved the lipid profile, without causing any hepatotoxicity or inducing any adverse affects, such as changes in blood pressure, heart rate and body weight which these may indirectly improve the diabetic condition [23]. Tea-infusions of Salvia officinalis have shown to be as effective as metformin, which is an oral anti-diabetic drug used for the treatment of type II diabetes and act by reducing liver glucose production as well as increases the action of insulin [33].

Cancer: Cancer is characterized by abnormal growth of cells which tend to proliferate in an uncontrolled way and in some cases spread to other parts of the body. The important factor in proliferating and spreading of cancer cells is the ability of tumors to produce large number of new blood vessels, known as angiogenesis. Most primary solid tumors are dependent on angiogenesis for survival, growth, invasion and metastasis. In a study, it was found that Salvia officinalis extract at pharmacological concentrations inhibits angiogenesis in vivo which could be a novel starting point for the development of a new anti-angiogenic drug [34]. Ursolic acid found in sage effectively inhibits angiogenesis, invasion of tumor cells and metastasis and suppresses the lung colonization of B16 melanoma cells in vivo [35].

Colorectal cancer is a common type of cancer and significant cause of mortality in Western societies. It develops by genetic and epigenetic alterations which 
transfer normal colon cells to proliferating cells. The study has shown that dietary compounds can change the epigenetic status. Many food plants are rich in bioactive compounds and have shown to posses anticancer properties. The effects of sage (Salvia officinalis) herbal tea drinking were studied on the prevention of colon cancer in rats. It was found that Salvia officinalis water extract significantly decreased the oxidative $\mathrm{H}_{2} \mathrm{O}_{2}-$ induced DNA damage in vitro [36].

Some diterpenoids isolated from the roots of $S$. officinalis have shown to have cytotoxic and DNAdamaging activity in human colon carcinoma Caco-2 cells and human hepatoma HepG2 cells in vitro conditions [10]. The sesquiterpene fraction of $S$. officinalis with the presence of $\alpha$-humulene, demonstrate a strong cytotoxic activity in human prostate carcinoma LNCaP cells [10]. Also trans-caryophyllene which is main component of sesquiterpene fraction in Salvia officinalis shows high cytotoxic activity against the melanotic melanoma and renal adenocarcinoma cells [8]. Presence of $\alpha$-humulene as a component of $S$. officinalis demonstrated a strong cytotoxic activity on the human prostate carcinoma LNCaP cells [8].

Salvia libanotica (Lebanese sage) is one of the largely used sage species in traditional medicine which have been used for many years to cure diseases such as abdominal pains, headaches, indigestions, and heart disorders [2]. The oil extract of this species was shown to possess strong antimicrobial and antitumor effects [2]. The components of Lebanese sage essential oil was identified by gas chromatography and three of the components which contains on average, 9.1\% Camphor (Ca), 1.3\% $\alpha$-Terpineol (Te) and 1.1\% Linalyl acetate (Ly) were found to be responsible for the oil antibacterial, antifungal, anti-inflammatory and antitumor effects [2]. In a study Ly, Te, and Ca synergistically induced cell cycle arrest and apoptosis resulting in the inhibition of the growth of human colon cancer cell lines, HCT-116 ( $\mathrm{P}_{53}+/+$ and $\mathrm{P}_{53} 3^{-/-}$) without any effect on the growth of normal human intestinal cell lines [2].

Cholesterol: The metabolite profile of Salvia miltiorrhiza is similar to common sage and recently, it was shown that an extract of Salvia miltiorrhiza was able to lower plasma cholesterol, LDL, and triglycerides as well as increase HDL levels in lipidemic rats [33].

The extract of Salvia officinalis is found to activate peroxisome proliferator-activated receptor gamma (PPAR $\gamma$ ) which is a regulator of genes involved in energy spending as well as lipid and glucose metabolism and its activation improves the HDL/LDL ratio and lowers triglycerides in serum, reduces insulin resistance and reduces size of adipose (fat) tissue [33].

Extracts from some sage species have been shown to be effective in the prevention of cardiovascular disease due to, at least in part, prevention of LDL-C oxidation [23].

Obesity: Overweight and obesity are recognized to be important risk factors for type II diabetes, dyslipidemia, hypertension and many other diseases. To regulate fat absorption, the effective way is, to reduce body weight and obesity. Pancreatic lipase is well known to play an important role in lipid digestion [37]. In several studies on anti-obese components from natural medicine, the effect of Salvia officinalis and its active components in pancreatic lipase activity and lipid digestion were investigated. The methanolic $(\mathrm{MeOH})$ extract from the leaves of Salvia officinalis L. significantly inhibited the pancreatic lipase activity, and suppressed serum triglyceride (TG) elevation in olive oil-loaded mice. Carnosic acid and carnosol are two of the diterpenes isolated from the methanolic extract of the Salvia officinalis with inhibiting activity on pancreatic lipase. Carnosic acid also significantly inhibited triglyceride elevation in olive oil-loaded mice and reduced the gain of body weight and the accumulation of epididymal fat weight in high fat diet-fed mice after 14 days. In the course of several studies on anti-obese components from natural medicine, the extract of Salvia officinalis leaves showed inhibitory effect against the pancreatic lipase activity and eventually was effective to reduce body weight and obesity [38].

Hot flashes: Menopause is considered as physiological adjustment process to an altered hormonal balance [39]. Menopausal symptoms include hot flashes, insomnia, night-time sweating, dizziness, headaches, and palpitations. These symptoms reflect adaptation of the body to estrogen deprivation which affects various central neurotransmitters.

Sage (Salvia officinalis) has been traditionally used to treat sweating and menopausal hot flashes as well as to alleviate associated menopausal symptoms [39]. The efficacy of sage for the treatment of hot flashes during menopause was proven by multi center open clinical trial [6]. A fresh sage preparation demonstrated clinical value in the treatment of hot flashes and associated menopausal symptoms. Once-daily application of the fresh sage extract, demonstrated good clinical value in terms of safety, efficacy, and tolerability in the treatment of menopausal hot flashes and climacteric symptoms, validated by statistical analysis and the clinically relevant verdict of patients and physicians. The study findings provide a scientific rationale for sage's use in folk medicine, offering a valuable option for patients and healthcare providers, seeking alternative approaches for the treatment of menopausal hot flashes and climacteric complaints [39].

Anti-bacteria: In a study done on the antibacterial effect of sage against selected food spoiling bacteria in vitro, indicates that the sage aqueous extract exerted significant antibacterial activity and it was most effective against Bacillus mycoids, Bacillus subtilis, Enterobacter cloacae, and Proteus sp. The work showed that sage along with different plant extracts was comparable to synthetic preservatives and the result confirmed that the aqueous extract of Salvia officinalis can be used in 
biotechnological field as a natural preservative ingredient in food industry [26].

The study of antibacterial activities of the essential oil of Salvia officinalis proved that sage essential oil in higher concentration exhibited a better efficiency than antibiotics against bacteria, especially against resistant bacteria to the antibiotics [5]. This has made sage essential oil a good alternative to the traditional antibiotics as well as food preservatives [5].

The finding of a study support the view that the hydroalcoholic extracts of Salvia officinalis has growth inhibitory effect on some dental caries causing bacteria, such as Streptococcus mutans, Lactobacillus rhamnosus and Actinomyces viscosus. Based on this study, and increasing interest on using traditional treatments instead of chemical solutions, Salvia officinalis with the bactericidal effect could be a natural remedy for the treatment of mouth and teeth diseases [40].

Anti-diarrhea: Based on the medicinal use of sage in diarrhea and abdominal spasm, the crude extract of sage was tested for its anti-diarrheal and antispasmodic activities using the in-vitro and in-vivo assays. A study demonstrated that the crude extract provides protection against diarrhea through inhibitory effect on gut motility by the presence of some gut relaxant components [7]. The data in a study suggests that the crude extract of $S$. officinalis possess anti-diarrheal and antispasmodic activities, mediated possibly through activation of voltage sensitive $\mathrm{K}^{+}$channels together with weak $\mathrm{Ca}^{++}$antagonist effect [7]. Therefore, this study provides pharmacological basis for the medicinal use of $S$. officinalis in hyperactive gut disorders such as abdominal colic and diarrhea [7].

Saftey: There are no reports of negative side effects as far we know associated with Salvia lavandulaefolia (or S. officinalis) despite of their usages for many centuries [29]. The normal usage of sage is very safe. However, there might be adverse effects for somebody using Salvia officinalis in excessive amount, which can be caused by the high content of thujone [6]. The studies have shown that Salvia lavandulaefolia compare to Salvia officinalis has similar compositions without the thujone content, which makes it more suitable to use for somebody concerned about the excessive usage of sage as a treatment [37].

\section{CONCLUSION}

Salvia species may represent natural, safe, and effective treatments for many diseases and their symptoms. In recent decades, with the increase of pharmacological knowledge about the beneficial effects of sage especially Salvia officinalis, these herbal medicines with antibacterial, antioxidant, anti-inflammatory, free radical scavenging and antitumor activities, have found to be very effective in the development of novel natural drugs to prevent, control and treat many minor health problems as well as more serious and complicated diseases such as diabetes, Alzheimer's and cancer.

$* * * * * * * * *$

\section{Author Contributions}

Rafie Hamidpour - Substantial contributions to conception and design, Analysis and interpretation of data, Revising it critically for important intellectual content, Final approval of the version to be published Soheila Hamidpour - Analysis and interpretation of data, Revising it critically for important intellectual content, Final approval of the version to be published

Mohsen Hamidpour - Analysis and interpretation of data, Revising it critically for important intellectual content, Final approval of the version to be published Mina Shahlari - Acquisition of data, Drafting the article, Final approval of the version to be published

\section{Guarantor}

The corresponding author is the guarantor of submission.

\section{Conflict of Interest}

Authors declare no conflict of interest.

\section{Copyright}

(C) Rafie Hamidpour et al. 2013; This article is distributed under the terms of Creative Commons attribution 3.0 License which permits unrestricted use, distribution and reproduction in any means provided the original authors and original publisher are properly credited. (Please see www.ijcasereportsandimages.com/copyright-policy.php for more information.)

\section{REFERENCES}

1. Nikavar B, Abolhasani L, Izadpanah H. Alpha-amylase inhibitory activities of six salvia species. Iranian Journal of Pharmaceutical Research 2008;7(4):297303.

2. Itani WS, El-Banna SH, Hassan SB, Larsson RL, Bazarbachi A, Gali-Muhtasib HU. Anti colon cancer components from Lebanese sage (Salvia libanotica) essential oil: Mechanistic basis. Cancer Biol Ther 2008 Nov;7(11):1765-3

3. Ayatollahi A, Shojaii A, Kobarfard F, Mohammadzadeh M, Choudhary M. Two flavones from Salvia leriaefolia. Iranian Journal of Pharmaceutical Research 2009;8(3):179-84.

4. Smidling D, Mitic-Culafic D, Vukovic-Gacic B, Simic D, Knezevic-Vukcevic J. Evaluation of antiviral activity of fractionated extracts of Sage Salvia officinalis L (Lamiaceae). Arch Biol Sci Belgrade 2008;60(1):4219.

5. Rami K, Li Z. Antimicrobial activity of essential oil of Salvia officinalis L. collected in Syria. African Journal of Biotechnology 2011;10(42):8397-402.

6. Walch SG, Tinzoh LN, Zimmermann BF, Stühlinger W, Lachenmeier DW. Antioxidant Capacity and 
Polyphenolic Composition as Quality Indicators for Aqueous Infusions of Salvia officinalis L. (sage tea). Front Pharmacol 2011 Dec 19;2:79.

7. Khan A, Najeeb-ur- Rahman, Alkharfy K, Gilani A. Antidiarrheal and antispasmodic activities of Salvia officinalis are mediated through activation of $\mathrm{K}+$ channels. A Journal of the Bangladesh Pharmacological Society 2011;6:111-6.

8. Loizzo MR, Tundis R, Menichini F, Saab AM, Statti GA, Menichini F. Cytotoxic activity of essential oils from Labiatae and Lauraceae families against in vitro human tumor models. Anticancer Res 2007 SepOct;27(5A):3293-9.

9. Radulescu V, Chiliment S, Oprea E. Capillary gas chromatography-mass spectrometry of volatile and semi-volatile compounds of Salvia officinalis. J Chromatogr A 2004 Feb 20;1027(1-2):121-6.

10. Hadri A, Gomez del Rio M, Sanz J, et al. Cytotoxic activity of a-humulene and transcaryo-phyllene from Salvia officinalis in animal and human tumor cells. An R Acad Nac Farm 2010;76(3):343-56.

11. Hussain A, Anwar F, Iqbal T, Bhatti I. Antioxidant attributes of four Lamiaceae essential oils. Pak J Bot 2011;43(2):1315-21.

12. Avato P, Fortunato I, Ruta C, D' Elia R. Glandular hairs and essential oils in micro propagated plants of Salvia officinalis L. Plant Science 2005;169:29-36.

13. Crotea R, Felton M, Felton M, Karp F, Kjonaas R. Relationship of camphor biosynthesis to leaf development in sage (Salvia officinalis). Plant Physiol 1981 Apr;67(4):820-4.

14. Baranauskiene R, Dambrauskiene E, Venskutonis P. Influence of harvesting time on the yield and chemical composition of sage (Salvia officinalis L.). Foodbalt 2011:105-9.

15. Kamatou P, Viljoen A, Steenkamp P. Antioxidant, anti-inflammatory activities and HPLC analysis of South African salvia species. Food Chemistry 2009.

16. Adams JD, Wang R, Yang J, Lien EJ. Preclinical and clinical examinations of Salvia miltiorrhiza and its tanshinones in ischemic conditions. Chin Med 2006 Nov 23;1:3.

17. Yurtseven, S, Cetin M, Sengiil T, Sogut B. Effect of sage extract (Salvia officinalis) on growth performance, blood parameters, oxidative stress and DNA damage in partridges. South African Journal of Animal Science 2008;38(2):145-2.

18. Baricevic D, Sosa S, Della Loggia R, et al. Topical antiinflammatory activity of Salvia officinalis L. leaves: The relevance of ursolic acid. J Ethnopharmacol 2001 May;75(2-3):125-32.

19. Eidi M, Eidi A, Bahar M. Effects of Salvia officinalis L. (sage) leaves on memory retention and its interaction with the cholinergic system in rats. Nutrition 2006 Mar;22(3):321-6.

20. Yadav S, Mukundan U. In vitro antioxidant properties of Salvia coccinea Buc'hoz ex etl. and Salvia officinalis L. Indian Journal of Fundamental and Applied Life Sciences 2011;1(3):232-8.

21. Nickavar B, Kamelinejad M, Izadpanah H. In vitro free radical scavenging activity of five salvia species. Pak J Pharm Sci 2007 Oct;20(4):291-4.

22. Aleksovski A, Sovova H. Supercritical Co2 extraction of Salvia officinalis L. The Journal of Supercritical Fluids 2007;40:239-45.
23. Sá CM, Ramos AA, Azevedo MF, Lima CF, FernandesFerreira M, Pereira-Wilson C. Sage tea drinking improves lipid profile and antioxidant defences in humans. Int J Mol Sci 2009 Sep 9;10(9):3937-50.

24. Lu Y, Foo LY. Flavonoid and phenolic glycosides from Salvia officinalis. Phytochemistry 2000 Oct;55(3):263-7.

25. Lu Y, Yeap Foo L. Salvianolic acid L, a potent phenolic antioxidant from Salvia officinalis. Tetrahedron Letters 2001;42:8223-5.

26. Stanojevic D, Comic L, Stefanovic O, Solujic-Sukdolak S. In vitro synergistic antibacterial activity of Salvia officinalis and some preservatives. Arch Biol Sci Belgrade 2010;62(1):175-83.

27. Perry NS, Bollen C, Perry EK, Ballard C. Salvia for dementia therapy: review of pharmacologyical activity and pilot tolerability clinical trial. Pharmacol Biochem Behav 2003 Jun;75(3):651-9.

28. Ferreira A, Proença C, Serralheiro ML, Araújo ME. The in vitro screening for acetyl cholinesterase inhibition and antioxidant activity of medicinal plants from Portugal. J Ethnopharmacol 2006 Nov 3;108(1):31-7.

29. Tildesley NT, Kennedy DO, Perry EK, Ballard CG, Wesnes KA, Scholey AB. Positive modulation of mood and cognitive performance following administration of acute doses of Salvia lavandulaefolia essential oil to healthy young volunteers. Physiol Behav 2005 Jan 17;83(5):699-709.

30. Akhondzadeh S, Noroozian M, Mohammadi M, Ohadinia S, Jamshidi AH, Khani M. Salvia officinalis extract in the treatment of patients with mild to moderate Alzheimer's disease: A double blind, randomized and placebo-controlled Trial. J Clin Pharm Ther 2003 Feb;28(1):53-9.

31. Iuvone T, De Filipis D, Esposito G, D’Amico A, Izzo A. The spice sage and its active ingredient rosmarinic acid protect $\mathrm{PC} 12$ cells from amyloidbeta Peptide-induced neurotoxicity. The Journal of Pharmacology and Experimental Therapeutics 2006 Jun;317(3):1143-9.

32. Moss L, Rouse M, Wesnes KA, Moss M. Differential effects of the aromas of Salvia species on memory and mood. Hum Psychopharmacol 2010 Jul;25(5):38896.

33. Christensen KB, Jørgensen M, Kotowska D, Petersen RK, Kristiansen K, Christensen LP. Activation of the nuclear receptor PPAR? by metabolites isolated from sage (Salvia officinalis L.). Journal of Ethnopharmacology 2010 Oct 28;132(1):127-33.

34. Keshavarz M, Bidmeshkipour A, Mostafavi A, Mansouri K, Mohamadi-Motlagh H. Anti tumor activity of Salvia officinalis is due to its antiangiogenic, anti-migratory and anti-proliferative effects. Cell Journal 2011;12(4):477-82.

35. Jedinak A, Muckova M, Kost'alova D, Maliar T, Masterova I. Antiprotease and antimetastatic activity of ursolic acid isolated from Salvia officinalis. Z Naturforsch C 2006 Nov-Dec;61(11-12):777-82.

36. Pedro D, Ramos A, Lima C, Baltazar F, PereiraWilson C. Modulation of DNA damage prevention and signaling pathways in diet induced colon cancer prevention. BMC Proceedings 2010;4:53.

37. Tildesley NT, Kennedy DO, Perry EK, et al. Salvia lavandulaefolia (Spanish sage) enhances memory in 
healthy young volunteers. Pharmacol Biochem Behav 2003 Jun;75(3):669-74.

38. Ninomiya K, Matsuda $\mathrm{H}$, Shimoda $\mathrm{H}$, et al. Carnosic acid, a new class of lipid absorption inhibitor from sage. Bioorg Med Chem Lett 2004 Apr 19;14(8):19436.

39. Bommer S, Klein P, Suter A. First time proof of sage's tolerability and efficacy in menopausal women with hot flushes. Adv Ther 2011 Jun;28(6):490-500.

40. Kermanshah H, Kamangar S, Arami S, et al. In vitro evaluation of antibacterial activity of hydroalcoholic extract of Salvia officinalis and Pimpinella anisum against carigenic bacteria. Journal of Dental Medicine Tehran University 2009;22(2):149-54.
Access full text article on other devices

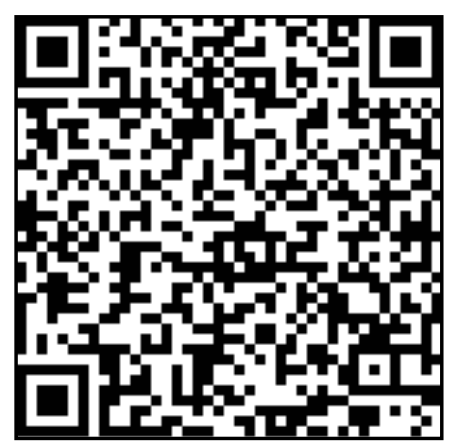

Access PDF of article on other devices

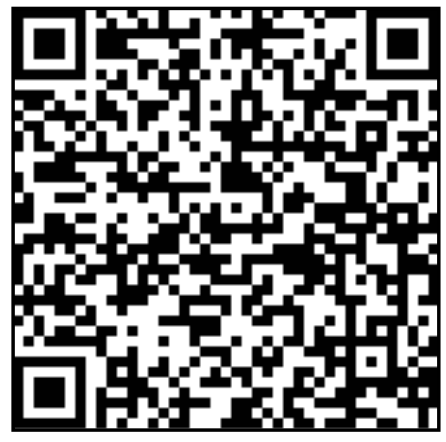

